\title{
Synthesis and Characterization of Novel Ruthenium(III) Complexes with Histamine
}

\author{
Jakob Kljun, ${ }^{1}$ Saša Petriček, ${ }^{1}$ Dušan Žigon, ${ }^{2}$ Rosana Hudej, ${ }^{1,3}$ \\ Damijan Miklavčič, ${ }^{3}$ and Iztok Turel ${ }^{1}$ \\ ${ }^{1}$ Faculty of Chemistry and Chemical Technology, University of Ljubljana, Aškerčeva 5, 1000 Ljubljana, Slovenia \\ ${ }^{2}$ Department of Environmental Sciences, Jožef Stefan Institute, Jamova c. 39, 1000 Ljubljana, Slovenia \\ ${ }^{3}$ Faculty of Electrical Engeneering, University of Ljubljana, Tržaška 25, 1000 Ljubljana, Slovenia
}

Correspondence should be addressed to Iztok Turel, iztok.turel@fkkt.uni-lj.si

Received 30 December 2009; Accepted 9 March 2010

Academic Editor: Spyros Perlepes

Copyright $\odot 2010$ Jakob Kljun et al. This is an open access article distributed under the Creative Commons Attribution License, which permits unrestricted use, distribution, and reproduction in any medium, provided the original work is properly cited.

Novel ruthenium(III) complexes with histamine $\left[\mathrm{RuCl}_{4}(\mathrm{dmso}-\mathrm{S})(\right.$ histamineH$\left.)\right] \cdot \mathrm{H}_{2} \mathrm{O}(\mathbf{1 a})$ and $\left[\mathrm{RuCl}_{4}\left(\mathrm{dmso}^{-S}\right)(\mathrm{histamineH})\right]$ (1b) have been prepared and characterized by X-ray structure analysis. Their crystal structures are similar and show a protonated amino group on the side chain of the ligand which is not very common for a simple heterocyclic derivative such as histamine. Biological assays to test the cytotoxicity of the compound $\mathbf{1 b}$ combined with electroporation were performed to determine its potential for future medical applications in cancer treatment.

\section{Introduction}

Before the discovery of cisplatin and its successful use as an anticancer agent in the 70s, metal complexes were rarely considered useful for medical applications. Afterwards, new cisplatin analogues (carboplatin, oxaliplatin) were developed and introduced into clinical use [1-3]. The development of platinum-drug resistance in cancer patients, the general toxicity and severe side effects of platinum drugs however required a different approach in the research of anticancer metal complexes [2].

Complexes of different metals were prepared and tested. Two ruthenium compounds, NAMI-A and KP1019 [4-6], are currently among the most successful candidates to enter the clinical practice. These two ruthenium(III) complexes have an octahedral geometry and contain four in-plane chlorido ligands as well as one dimethylsulfoxido and one imidazolo (NAMI-A) or two indazolo ligands (KP1019) in trans positions. The aforementioned compounds are the chosen representatives of two larger classes of compounds bearing nitrogen-bound aromatic heterocycles developed by the Alessio and Keppler research groups, respectively $[4,7,8]$.
Histamine (4-(2-Aminoethyl)- $1 H$-imidazole, see Scheme 2 ) is a molecule that performs various functions in the body, the most important being the gastric acid secretion and the triggering of the symptoms of an allergic reaction such as vasodilatation, bronchoconstriction, bronchial muscle contraction, pain, and itching.

Most of the metal complexes in use in current cancer treatment have an intracellular target and the plasma membrane can represent a considerable barrier. Electroporation or electropermeabilization is a process where exposing cells to specific electrical pulses results in temporary formation of hydrophilic pores in the cell membrane. Thus temporally increased cell permeability enables extracellular molecules with otherwise hampered transmembrane transport to enter the cells. Electroporation is used in a variety of biotechnological and medical applications. It has been proven that combining electroporation with chemotherapy potentiates the cytotoxicity of drugs when the drugs' efficacy is limited by its uptake in the cell [9-13].

The aim of this study was to prepare and characterize new ruthenium NAMI-type compounds, to test their in vitro cytotoxicity and study the influence of electroporation on the cytotoxic activity of the synthesized compounds. 


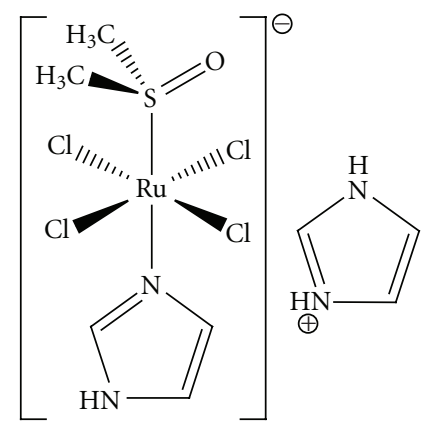

NAMI-A

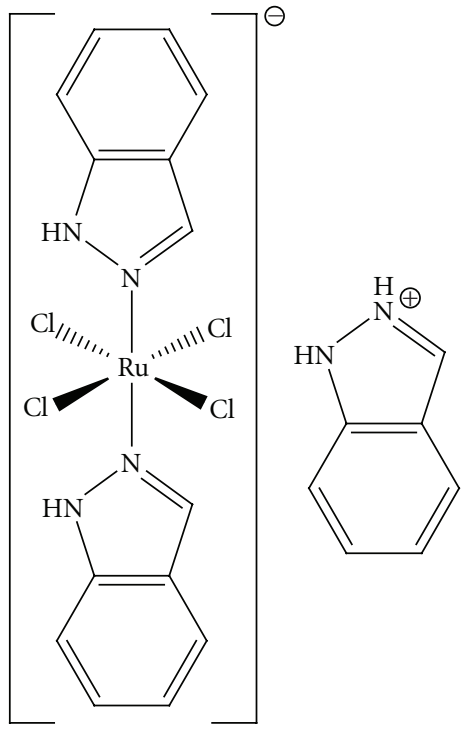

KP1019

Scheme 1: NAMI-A and KP1019.

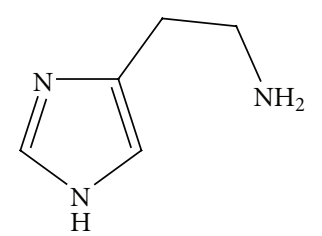

Scheme 2: Histamine.

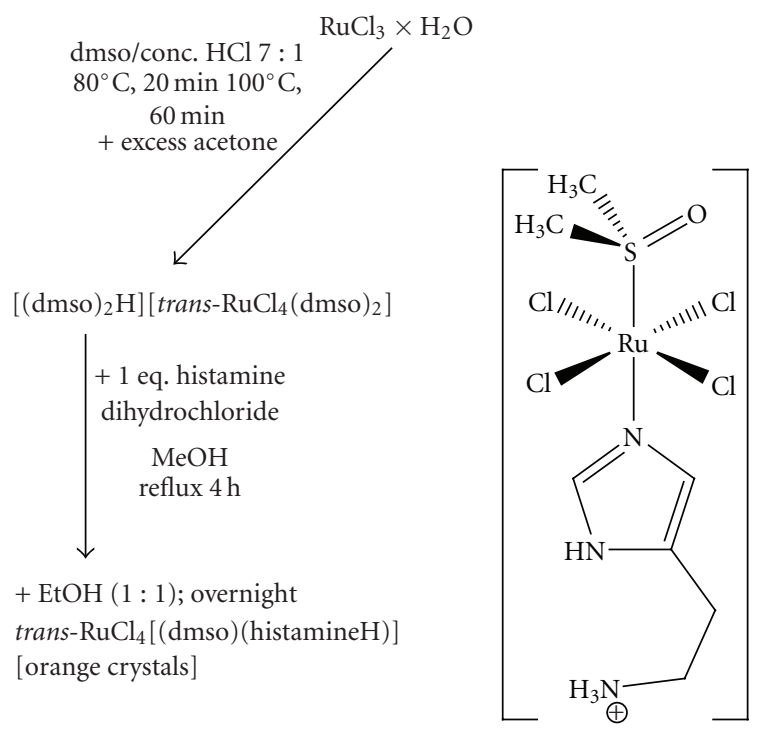

Scheme 3: Two step synthesis and structure of the novel ruthenium complex with histamine.

\section{Experimental}

2.1. Materials and Instruments. Ruthenium(III) chloride hydrate, histamine dihydrochloride, and the solvents

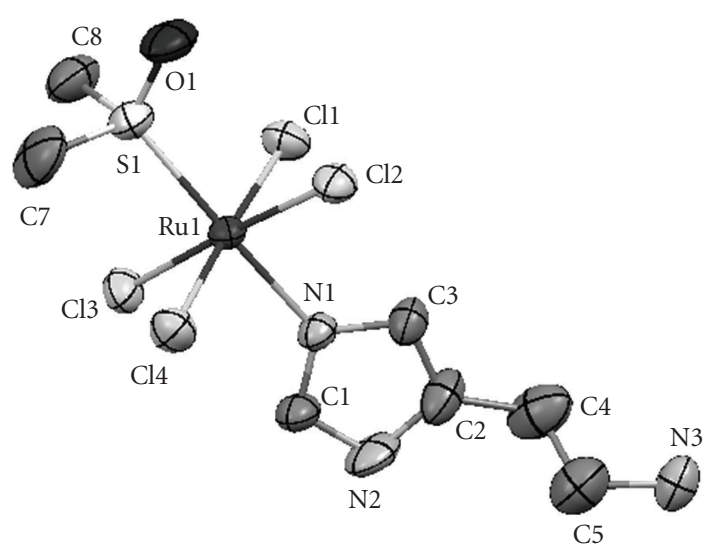

Figure 1: Asymmetric unit of the crystal structure of complex $\mathbf{1 b}$. The ellipsoids are shown at $50 \%$ probability.

(dimethylsulfoxide, concentrated hydrochloric acid, methanol, ethanol, and acetone) were purchased by Sigma-Aldrich and used without further purification.

2.1.1. Infrared Spectroscopy. Infrared spectra (ATR) were recorded on a Perkin-Elmer Spectrum 100 spectrometer. The measurements were made in the range from 4000 to $600 \mathrm{~cm}^{-1}$.

2.1.2. Electrospray Ionization Mass Spectrometry. Mass measurements were run on a hybrid quadrupole time of flight mass spectrometer Q-Tof Premier (Waters Micromass, Manchester, UK), equipped with an orthogonal Z-spray electrospray (ESI) interface.

Water sample solution was introduced directly through syringe pump at a flow rate $5 \mu \mathrm{L} / \mathrm{min}$. Compressed nitrogen 


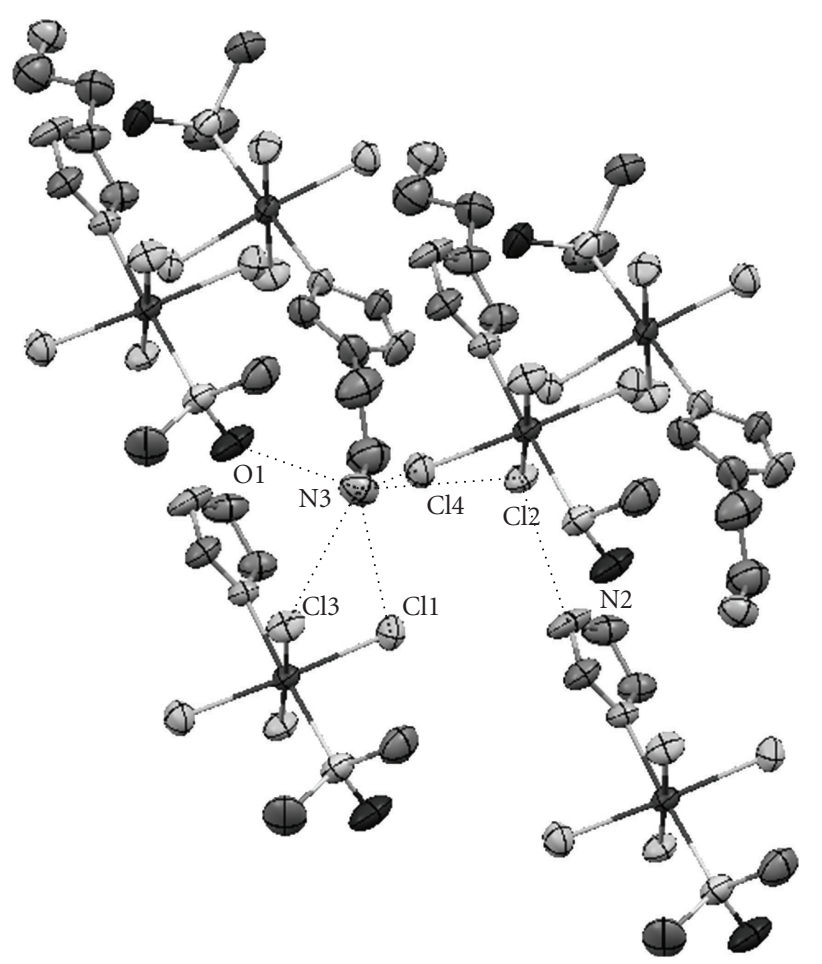

FIGURE 2: The hydrogen bonds in the crystal structure of compound 1b. The ammonioethyl groups of the lower two asymmetric units are omitted for clarity.

(99.999\%, Messer Slovenia) was used as both the drying and the nebulizing gas. The nebulizer gas flow rate was set to approximately $20 \mathrm{~L} / \mathrm{h}$ and the desolvation gas flow rate to $600 \mathrm{~L} / \mathrm{h}$. A cone voltage of $30 \mathrm{~V}$ and a capillary voltage of $2.9 \mathrm{kV}$ were used in positive ion mode. The desolvation temperature was set to $150^{\circ} \mathrm{C}$ and the source temperature to $100^{\circ} \mathrm{C}$. The mass resolution of approximately $9500 \mathrm{fwhm}$ was used for determination of elemental composition with TOF mass spectrometer. MS and MS/MS spectra were acquired in centroid mode over an $\mathrm{m} / \mathrm{z}$ range of $50-1000$ in scan time $1 \mathrm{~s}$ and inter scan time $0.1 \mathrm{~s}$. The detector potential was set to $1850 \mathrm{~V}$. Reproducible and accurate mass measurements at approximate 10000 mass resolution were obtained using an electrospray dual sprayer with leucine enkephalin $\left([\mathrm{MH}]^{+}=\right.$ 556.2771) as a reference compound, introduced into the mass spectrometer alternating with a sample solution.

The data station operating software was Mass Lynx v. 4.1 (Micromass, Manchester).

Interpretation of peaks in mass spectra and identification of particular fragment ions were confirmed with elemental composition mass measurements of these ions at high resolution.

2.1.3. CHN Elemental Analysis. Elemental analyses were performed on a Perkin-Elmer Elemental analyzer $2400 \mathrm{CHN}$.

2.1.4. X-Ray Structure Analysis. X-ray diffraction data were collected on a Nonius Kappa CCD diffractometer at $150 \mathrm{~K}$ for compound 1a and at room temperature for compound
1 b using graphite monochromated $\mathrm{Mo}-K_{\alpha}$ radiation and processed using DENZO [14] program. The structures were solved using SIR92 [15]. A full-matrix least-squares refinement on $F$ magnitudes with anisotropic displacement factors for all nonhydrogen atoms using SHELXL [16] was employed. The drawings were prepared with the Mercury program [17]. Hydrogen atoms were placed in geometrically calculated positions and were refined using a riding model.

The crystallographic data for compounds $\mathbf{1 a}$ and $\mathbf{1} \mathbf{b}$ have been deposited with the CCDC as supplementary material with the deposition numbers CCDC 759890 and 759818, respectively (see Supplementary Material available online at doi:10.1155/2010/183097).

2.2. Syntheses. Syntheses of $\left[\mathrm{RuCl}_{4}(\mathrm{dmso}-\mathrm{S})\right.$ (histamine$\mathrm{H})] \cdot \mathrm{H}_{2} \mathrm{O}(\mathbf{1 a})$ and $\left[\mathrm{RuCl}_{4}(\mathrm{dmso}-\mathrm{S})(\right.$ histamine $\left.\mathrm{H})\right](\mathbf{1 b})$ : the synthesis of compounds $\mathbf{1 a}$ and $\mathbf{1 b}$ consists of two steps (see Scheme 3). The first step is the preparation of a ruthenium precursor $\mathbf{P 1}\left(\mathrm{dmso}_{2} \mathrm{H}\right)\left[\right.$ trans- $\left.\mathrm{RuCl}_{4}(\mathrm{dmso}-\mathrm{S})_{2}\right]$. This compound was prepared according to the literature [18]. $200 \mathrm{mg}$ of $\mathbf{P 1}$ and $70 \mathrm{mg}$ of histamine dihydrochloride were dissolved in $15 \mathrm{~mL}$ of methanol and refluxed for 4 hours. After a slow evaporation of the solvent, only a few red crystals of 1a were obtained. The X-ray structure analysis showed the presence of a solvate water in a molecule. Despite considerable effort, we were not able to obtain such crystals again. Crystals of compound $\mathbf{1 b}$ were later obtained by adding $15 \mathrm{~mL}$ of ethanol to the reaction mixture and the solution was left to stand in an open flask. Overnight snowflake-like crystalline orange solid formed. The crystals were washed with cold acetone and diethylether and dried at $50^{\circ} \mathrm{C}$ for 30 minutes. Similar crystals although of lower quality were obtained by addition of isopropanol, n-pentanol or ethyl acetate, instead of ethanol, to the reaction mixture.

IR (ATR): 3226 (sh), 3115 (s), 2923 (w), 1597 (w), 1578 (w), 1504 (sh), 1480 (m), 1402 (m), 1231 (w), 1111 (sh), 1082 (s), 1016 (s), 968 (s), 934 (s), 928 (sh), 840 (s), 684 (w), 658 (m) $\mathrm{cm}^{-1}$.

CHN (only 1b): Calc. C 19,41\%, H 3,72\%, N 9,70\%; Found: C 19,78\%, H 3,67\%, N 9,49\%.

ESI-MS (in $\mathrm{H}_{2} \mathrm{O}$ solution): m/z 361, 325, 299, 264.

2.3. Biological Activity Assays. Murine melanoma cell line B16F1 (European Collection of Cell Cultures, UK) was tested in vitro to determine cytotoxic effect of compound $\mathbf{1 b}$ in combination with or without electroporation. B16F1 cell suspension $\left(22 \cdot 10^{6}\right.$ cells $\left./ \mathrm{mL}\right)$ was prepared in low conductive electroporation buffer $\left(10 \mathrm{mM}\left(\mathrm{Na}_{2} \mathrm{HPO}_{4} / \mathrm{NaH}_{2} \mathrm{PO}_{4}\right.\right.$, $\mathrm{pH}$ 7.4) with $1 \mathrm{mM} \mathrm{MgCl}_{2}$ and $250 \mathrm{mM}$ sucrose). Different concentrations of compound $\mathbf{1} \mathbf{b}$ were added to cell suspension to reach final concentrations of $0.01,0.1$, and $1 \mathrm{mM}$. Immediately after incubation $(<0.5 \mathrm{~min})$, a drop of cell suspension was placed between two flat parallel stainlesssteel electrodes $2 \mathrm{~mm}$ apart and a train of electric pulses ( 8 pulses, $800 \mathrm{~V} / \mathrm{cm}, 100 \mu \mathrm{s}, 1 \mathrm{~Hz}$ ) was applied with an electroporator Cliniporator (Igea, Carpi, Italy). The same procedure without electric pulses was used for cells exposed to different concentrations of $\mathbf{1 b}$ without electroporation. 


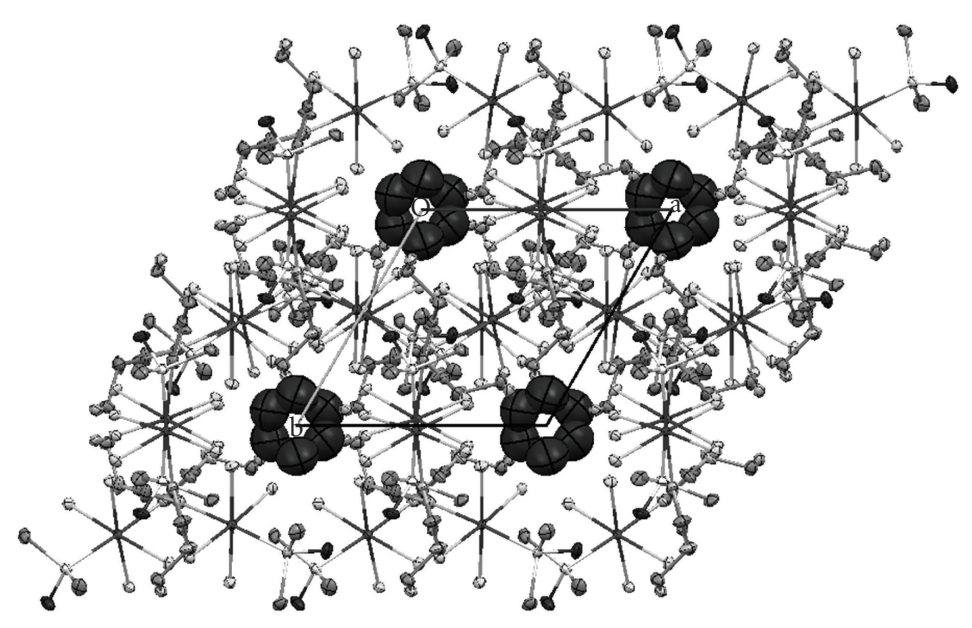

FIGURE 3: The packing in the crystal structure of compound 1a along the $z$ axis.

TABle 1: Crystal data and structure refinement for compounds $\mathbf{1 a}$ and $\mathbf{1 b}$.

\begin{tabular}{|c|c|c|}
\hline & Compound 1a & Compound $\mathbf{1 b}$ \\
\hline Empirical formula & $\mathrm{C}_{7} \mathrm{H}_{16} \mathrm{Cl}_{4} \mathrm{~N}_{3} \mathrm{O}_{2} \mathrm{RuS}$ & $\mathrm{C}_{7} \mathrm{H}_{16} \mathrm{Cl}_{4} \mathrm{~N}_{3} \mathrm{ORuS}$ \\
\hline Formula weight & $449.16 \mathrm{~g} / \mathrm{mol}$ & $433.16 \mathrm{~g} / \mathrm{mol}$ \\
\hline Temperature & $150(2) \mathrm{K}$ & $293(2) \mathrm{K}$ \\
\hline Wavelength & $0.71073 \AA$ & $0.71073 \AA$ \\
\hline Crystal system & Triclinic & Monoclinic \\
\hline Space group & $P 3121$ & $C 2 / c$ \\
\hline \multirow{6}{*}{ Unit cell dimensions } & $a=8.233 \AA$ & $a=14.4860(8) \AA$ \\
\hline & $b=8.233 \AA$ & $b=7.8741(3) \AA$ \\
\hline & $c=38.9269(3) \AA$ & $c=27.3464(15) \AA$ \\
\hline & $\alpha=90^{\circ}$ & $\alpha=90^{\circ}$ \\
\hline & $\beta=90^{\circ}$ & $\beta=91.457(2)^{\circ}$ \\
\hline & $\gamma=120^{\circ}$ & $\gamma=90^{\circ}$ \\
\hline Volume & $2284.943(18) \AA^{3}$ & $3118.2(3) \AA^{3}$ \\
\hline$Z$ & 6 & 8 \\
\hline Density (calculated) & $1.959 \mathrm{~g} / \mathrm{cm}^{3}$ & $1.845 \mathrm{~g} / \mathrm{cm}^{3}$ \\
\hline Absorption coefficient & $1.864 \mathrm{~mm}^{-1}$ & $1.813 \mathrm{~mm}^{-1}$ \\
\hline$F(000)$ & 1338 & 1720 \\
\hline Crystal size & $0.1 \times 0.1 \times 0.1 \mathrm{~mm}$ & $0.08 \times 0.05 \times 0.05 \mathrm{~mm}$ \\
\hline Theta range for data collection & 3.26 to $28.71^{\circ}$ & 3.22 to $27.49^{\circ}$ \\
\hline Reflections collected & 7263 & 5747 \\
\hline Independent reflections & $3830[R($ int $)=0.0166]$ & $3501[R($ int $)=0.0290]$ \\
\hline Refinement method & Full-matrix least-squares on $F^{2}$ & Full-matrix least-squares on $F^{2}$ \\
\hline Data/restraints/parameters & $3830 / 0 / 166$ & $3501 / 0 / 172$ \\
\hline Goodness-of-fit on $F^{2}$ & 1.068 & 1.080 \\
\hline Final $R$ indices $[I>2 \operatorname{sigma}(I)]$ & $R_{1}^{\mathrm{a}}=0.0236, w R_{2}^{\mathrm{b}}=0.0571$ & $R_{1}=0.0500, w R_{2}=0.1120$ \\
\hline$R$ indices (all data) & $R_{1}=0.0261, w R_{2}=0.0583$ & $R_{1}=0.0761, w R_{2}=0.1229$ \\
\hline Largest diff. peak and hole & 1.229 and $-0.686 \mathrm{e} \cdot \AA^{3}$ & 1.098 and $-0.560 \mathrm{e} \cdot \AA^{-3}$ \\
\hline
\end{tabular}

${ }^{\mathrm{a}} R_{1}=\sum\left(\left|F_{o}\right|-\left|F_{c}\right|\right) / \sum\left|F_{o}\right| ;{ }^{\mathrm{b}} w R_{2}=\left\{\left[w\left(F_{o}^{2}-F_{c}^{2}\right)^{2}\right] / \sum\left[w F_{o}^{2}\right]\right\}^{1 / 2}$

In addition, we tested cytotoxic effect of $\mathbf{1} \mathbf{b}$ after prolonged incubation time (60 min, without electroporation). Cell viability was measured $72 \mathrm{~h}$ after treatment using the MTSbased Cell Titer $96 \mathrm{AQ}_{\text {ueous }}$ One Solution Cell Proliferation Assay (Promega, Madison, WI, USA). Absorption at $490 \mathrm{~nm}$ wavelength $\left(\mathrm{A}_{490}\right)$ was measured with a spectrophotometer Tecan infinite M200 (Tecan, Switzerland). Cell viability (C.V.) of treated cells (tr) was calculated using the formula: C.V. $=\left(\mathrm{A}_{490}\right)_{\mathrm{tr}} /\left(\mathrm{A}_{490}\right)_{\mathrm{c}} \times 100[\%]$, taking the cell viability of the control I as $100 \%$. Statistical analysis was performed 
using One-Way ANOVA test and SigmaStat statistical software (SPSS, Chicago, USA).

\section{Results and Discussion}

3.1. Synthesis and Crystal Structure. Several complexes of the NAMI and KP families bearing nitrogen-bound simple heterocycles or smaller biologically active molecules were already synthesized and investigated for biological applications [4, $7,19,20]$. Most of the NAMI analogues were synthesized by mixing a suspension of $\mathbf{P} \mathbf{1}$ in acetone and adding the equivalent amount of the ligand and then recrystallizing the product either from hot acetone or other solvents. In our case this synthetic route was not appropriate due to the low solubility of compound $\mathbf{1 b}$ in acetone or other solvents except in water and methanol. The reaction was thus performed in methanol and another less volatile and less polar solvent was added later. Similar crystals although of lower quality were obtained by addition of isopropanol, npentanol, or ethyl acetate instead of ethanol to the reaction mixture. The crystals were cut and were suitable for Xray structure analysis. The experimental data is shown in Table 1.

The asymmetric unit of compound $\mathbf{1 b}$ is shown in Figure 1. Selected bond lengths and hydrogen bond short contact distances are presented in Tables 2 and 3 , respectively.

The crystal structure of compounds $\mathbf{1 a}$ and $\mathbf{1 b}$ does not differ significantly from the other NAMI-type compounds. Compounds $\mathbf{1 a}$ and $\mathbf{1 b}$ have a distorted octahedral geometry with four in-plane chloride anions surrounding the $\mathrm{Ru}$ (III) ion in addition to a sulfur atom from an $\mathrm{S}$ bonded dimethylsulfoxide molecule and a nitrogen atom from the histamine molecule in axial positions. The main difference to most of the NAMI-type compounds which are anionic complexes is the protonated amino group on the side chain of the histamine moiety (hence histamineH is used in the formula) that gives compounds $\mathbf{1 a}$ and $\mathbf{1 b}$ a neutral charge. This structural feature is however more common in NAMI-type compounds with a purine derivative as the nitrogen ligand [21]. The hydrogen atoms on the amino group (H3A, H3B and $\mathrm{H} 3 \mathrm{C}$ ) form hydrogen bonds with the four chloride atoms and the dmso oxygen. The $\mathrm{Cl} 2$ chloride atom forms an additional hydrogen bond with the hydrogen on the imidazole moiety (H2) which results in a slightly longer $\mathrm{Ru}-\mathrm{Cl} 2$ distance (see Tables 2 and 3 and Figures 1 and 2). Compound 1a exhibits an additional hydrogen bond between the water molecule and one of the chloride anions. It was not possible to locate the positions of two hydrogen atoms bonded to oxygen in a water molecule of the complex 1a by difference Fourier maps.

Another interesting feature of the crystal structure of compound $\mathbf{1 a}$ is the formation of channels along $z$ axis where the water molecules are located (see Figure 3).

3.2. Electrospray Ionization Mass Spectrometry. Compound 1b was also characterized by electrospray ionization mass spectrometry. The peaks in the mass spectrum and their
TABLE 2: Selected bond lengths in compounds $\mathbf{1 a}, \mathbf{1 b}$ and NAMI $[22]\left(\mathrm{Na}\left[\mathrm{RuCl}_{4}(S\right.\right.$-dmso)(imidazole) $\left.]\right)$.

\begin{tabular}{lccc}
\hline & 1a & 1b & NAMI \\
\hline $\mathrm{Ru}-\mathrm{Cl}_{1}$ & $2.355(2)$ & $2.359(2)$ & $2.3403(9)$ \\
$\mathrm{Ru}-\mathrm{Cl}_{2}$ & $2.364(2)$ & $2.364(2)$ & $2.3227(8)$ \\
$\mathrm{Ru}-\mathrm{Cl}_{3}$ & $2.356(2)$ & $2.343(2)$ & $2.3588(9)$ \\
$\mathrm{Ru}-\mathrm{Cl}_{4}$ & $2.358(2)$ & $2.356(2)$ & $2.3447(8)$ \\
$\mathrm{Ru}-\mathrm{S}$ & $2.300(2)$ & $2.298(2)$ & $2.2956(6)$ \\
$\mathrm{Ru}-\mathrm{N}$ & $2.096(2)$ & $2.097(2)$ & $2.081(2)$ \\
\hline
\end{tabular}

TABLE 3: Selected hydrogen bond short contact distances in compound $\mathbf{1 b}$.

\begin{tabular}{lcc}
\hline $\mathrm{D}-\mathrm{H} \cdots \mathrm{A}$ & $\mathrm{D}-\mathrm{A}(\AA)$ & angle DHA $\left(^{\circ}\right)$ \\
\hline $\mathrm{N}_{2}-\mathrm{H}_{2} \cdots \mathrm{Cl}_{2}$ & $3.218(6)$ & 151 \\
$\mathrm{~N}_{3}-\mathrm{H}_{3} \mathrm{~A} \cdots \mathrm{Cl}_{2}$ & $3.331(6)$ & 138 \\
$\mathrm{~N}_{3}-\mathrm{H}_{3} \mathrm{~A} \cdots \mathrm{Cl}_{4}$ & $3.306(6)$ & 140 \\
$\mathrm{~N}_{3}-\mathrm{H}_{3} \mathrm{~B} \cdots \mathrm{Cl}_{1}$ & $3.308(6)$ & 149 \\
$\mathrm{~N}_{3}-\mathrm{H}_{3} \mathrm{~B} \cdots \mathrm{Cl}_{3}$ & $3.349(6)$ & 131 \\
$\mathrm{~N}_{3}-\mathrm{H}_{3} \mathrm{C} \cdots \mathrm{O}_{1}$ & $2.889(6)$ & 172 \\
\hline
\end{tabular}

TABLE 4: Main peaks in the ESI-MS spectrum of compound $\mathbf{1 b}$ and respective assignments.

\begin{tabular}{lc}
\hline $\mathrm{m} / \mathrm{z}$ & fragment \\
\hline 264 & $\mathrm{RuCl}($ histamine $)(\mathrm{OH})$ \\
299 & $\mathrm{RuCl}_{2}$ (histamine $)(\mathrm{OH})$ \\
325 & $\mathrm{RuCl}_{(\text {dmso })(\text { histamine })}$ \\
361 & $\mathrm{RuCl}_{2}($ dmso $)$ (histamine) \\
\hline
\end{tabular}

respective assignments are presented in Table 4 . The data confirm a partial hydrolysis of the compound in water solution. Such behavior is usual for the NAMI-type compounds which undergo a rather quick dissociation of two of the chloride ligands and/or the dmso molecule [23].

3.3. Biological Activity. Previous studies have shown that while NAMI-A is inactive against $\mathrm{B} 16 \mathrm{~F} 1$ cells in vitro, it shows remarkable activity at relatively low concentrations when combined with electroporation [24]. On the other hand compound $\mathbf{1 b}$ shows no activity at any of the tested concentrations (up to $1 \mathrm{mM}$ ) either by itself or in combination with electroporation.

As Dyson and Sava suggest [25], the cytotoxicity of a compound as one of the main criteria in the preliminary screenings when looking for a potential drug candidate should be considered with some caution. NAMI-A for example, showed remarkable antimetastatic properties despite very low cytotoxicity. Further investigations of the biological activity of the histaminic analogue and the study of the interactions with different proteins are being planned. 


\section{Acknowledgments}

Financial support from the Slovenian Research Agency (ARRS) through projects P1-0175, P2-0249, and J1-02000103-008 is gratefully acknowledged. This work was performed within the framework of COST Action D39. Jakob Kljun is grateful to ARRS for funding through a junior researcher grant. Jakob Kljun would also like to thank Marta Kasunič for her aid and advice on crystal structure solving.

\section{References}

[1] E. Wiltshaw, "Cisplatin in the treatment of cancer: the first metal anti-tumour drug," Platinum Metals Review, vol. 23, no. 3, pp. 90-98, 1979.

[2] L. Kelland, "The resurgence of platinum-based cancer chemotherapy," Nature Reviews Cancer, vol. 7, no. 8, pp. 573584, 2007.

[3] T. W. Hambley, "Developing new metal-based therapeutics: challenges and opportunities," Dalton Transactions, no. 43, pp. 4929-4937, 2007.

[4] E. Alessio, G. Mestroni, A. Bergamo, and G. Sava, "Ruthenium antimetastatic agents," Current Topics in Medicinal Chemistry, vol. 4, no. 15, pp. 1525-1535, 2004.

[5] C. G. Hartinger, S. Zorbas-Seifried, M. A. Jakupec, B. Kynast, H. Zorbas, and B. K. Keppler, "From bench to bedside-preclinical and early clinical development of the anticancer agent indazolium trans-[tetrachlorobis $(1 \mathrm{H}$ indazole)ruthenate(III)] (KP1019 or FFC14A)," Journal of Inorganic Biochemistry, vol. 100, no. 5-6, pp. 891-904, 2006.

[6] C. G. Hartinger, M. A. Jakupec, S. Zorbas-Seifried, et al., "KP1019, a new redox-active anticancer agent-preclinical development and results of a clinical phase I study in tumor patients," Chemistry and Biodiversity, vol. 5, no. 10, pp. 2140 2155, 2008.

[7] E. Reisner, V. B. Arion, A. Eichinger, et al., "Tuning of redox properties for the design of ruthenium anticancer drugspart 2: syntheses, crystal structures, and electrochemistry of potentially antitumor $\left[\mathrm{Ru}^{\mathrm{III} / \mathrm{II}} \mathrm{Cl}_{6-n}(\text { Azole })_{n}\right]^{z}(n=3,4,6)$ complexes," Inorganic Chemistry, vol. 44, no. 19, pp. 67046716, 2005.

[8] I. Bratsos, S. Jedner, T. Gianferrara, and E. Alessio, "Ruthenium anticancer compounds: challenges and expectations," Chimia, vol. 61, no. 11, pp. 692-697, 2007.

[9] E. H. Serpersu, K. Kinosita Jr., and T. Y. Tsong, "Reversible and irreversible modification of erythrocyte membrane permeability by electric field," Biochimica et Biophysica Acta, vol. 812, no. 3, pp. 779-785, 1985.

[10] J. Teissie, M. Golzio, and M. P. Rols, "Mechanisms of cell membrane electropermeabilization: a minireview of our present (lack of ?) knowledge," Biochimica et Biophysica Acta, vol. 1724, no. 3, pp. 270-280, 2005.

[11] M. Pavlin and D. Miklavčič, "Theoretical and experimental analysis of conductivity, ion diffusion and molecular transport during cell electroporation-relation between short-lived and long-lived pores," Bioelectrochemistry, vol. 74, no. 1, pp. 3846, 2008.

[12] S. Orlowski, J. Belehradek Jr., C. Paoletti, and L. M. Mir, “Transient electropermeabilization of cells in culture: increase of the cytotoxicity of anticancer drugs," Biochemical Pharmacology, vol. 37, no. 24, pp. 4727-4733, 1988.
[13] G. Serša, M. Čemažar, and D. Miklavčičc "Antitumor effectiveness of electrochemotherapy with cis-diamminedichloroplatinum(II) in mice," Cancer Research, vol. 55, no. 15, pp. 34503455, 1995.

[14] Z. Otwinowski and W. Minor, "Processing of X-ray diffraction data collected in oscillation mode," Methods in Enzymology, vol. 276, pp. 307-326, 1997.

[15] A. Altomare, M. C. Burla, M. Camalli, et al., "SIR97: a new tool for crystal structure determination and refinement," Journal of Applied Crystallography, vol. 32, no. 1, pp. 115-119, 1999.

[16] G. M. Sheldrick, "A short history of SHELX," Acta Crystallographica Section A, vol. 64, no. 1, pp. 112-122, 2008.

[17] C. F. Macrae, P. R. Edgington, P. McCabe, et al., "Mercury: visualization and analysis of crystal structures," Journal of Applied Crystallography, vol. 39, no. 3, pp. 453-457, 2006.

[18] E. Alessio, G. Balducci, M. Calligaris, G. Costa, W. M. Attia, and G. Mestroni, "Synthesis, molecular structure, and chemical behavior of hydrogen trans-bis(dimethyl sulfoxide)tetrachlororuthenate(III) and mer-trichlorotris(dimethyl sulfoxide)ruthenium(III): the first fully characterized chloridedimethyl sulfoxide-ruthenium(III) complexes," Inorganic Chemistry, vol. 30, no. 4, pp. 609-618, 1991.

[19] D. Griffith, S. Cecco, E. Zangrando, A. Bergamo, G. Sava, and C. J. Marmion, "Ruthenium(III) dimethyl sulfoxide pyridinehydroxamic acid complexes as potential antimetastatic agents: synthesis, characterisation and in vitro pharmacological evaluation," Journal of Biological Inorganic Chemistry, vol. 13, no. 4, pp. 511-520, 2008.

[20] I. Turel, M. Pečanac, A. Golobič, et al., "Solution, solid state and biological characterization of ruthenium(III)-DMSO complexes with purine base derivatives," Journal of Inorganic Biochemistry, vol. 98, no. 2, pp. 393-401, 2004.

[21] A. García-Raso, J. J. Fiol, A. Tasada, et al., "Ruthenium complexes with purine derivatives: syntheses, structural characterization and preliminary studies with plasmidic DNA," Inorganic Chemistry Communication, vol. 8, no. 9, pp. 800-804, 2005.

[22] E. Alessio, G. Balducci, A. Lutman, G. Mestroni, M. Calligaris, and W. M. Attia, "Synthesis and characterization of two new classes of ruthenium(III)-sulfoxide complexes with nitrogen donor ligands (L): $\mathrm{Na}\left[\right.$ trans $\left.-\mathrm{RuCl}_{4}\left(\mathrm{R}_{2} \mathrm{SO}\right)(\mathrm{L})\right]$ and mer, cis- $\mathrm{RuCl}_{3}\left(\mathrm{R}_{2} \mathrm{SO}\right)\left(\mathrm{R}_{2} \mathrm{SO}\right)(\mathrm{L})$. The crystal structure of $\mathrm{Na}\left[\right.$ trans $\left.-\mathrm{RuCl}_{4}(\mathrm{DMSO})\left(\mathrm{NH}_{3}\right)\right] \cdot 2 \mathrm{DMSO}, \mathrm{Na}\left[\right.$ trans $-\mathrm{RuCl}_{4}$ $(\mathrm{DMSO})(\mathrm{Im})] \cdot \mathrm{H}_{2} \mathrm{O}, \mathrm{Me}_{2} \mathrm{CO}(\mathrm{Im}=$ imidazole $)$ and mer, cis- $\mathrm{RuCl}_{3}$ (DMSO)(DMSO) $\left(\mathrm{NH}_{3}\right)$," Inorganica Chimica Acta, vol. 203, no. 2, pp. 205-217, 1993.

[23] G. Mestroni, E. Alessio, G. Sava, S. Pacor, M. Coluccia, and A. Boccarelli, "Water-soluble ruthenium(III)-dimethyl sulfoxide complexes: chemical behaviour and pharmaceutical properties," Metal-Based Drugs, vol. 1, no. 1, pp. 41-63, 1993.

[24] A. Bicek, I. Turel, M. Kanduser, and D. Miklavcic, "Combined therapy of the antimetastatic compound NAMIA and electroporation on B16F1 tumour cells in vitro," Bioelectrochemistry, vol. 71, no. 2, pp. 113-117, 2007.

[25] P. J. Dyson and G. Sava, "Metal-based antitumour drugs in the post genomic era," Dalton Transactions, no. 16, pp. 1929-1933, 2006. 


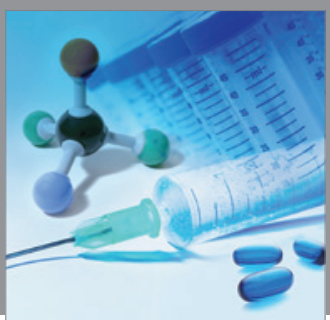

International Journal of

Medicinal Chemistry

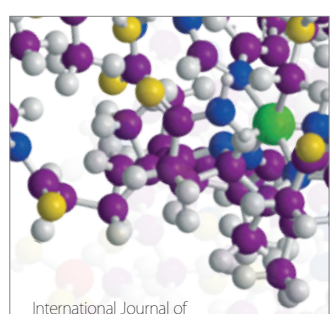

Carbohydrate Chemistry

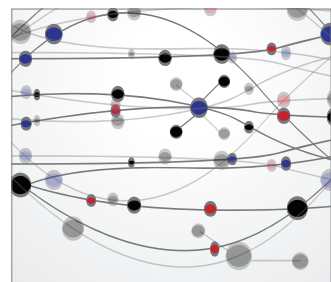

The Scientific World Journal
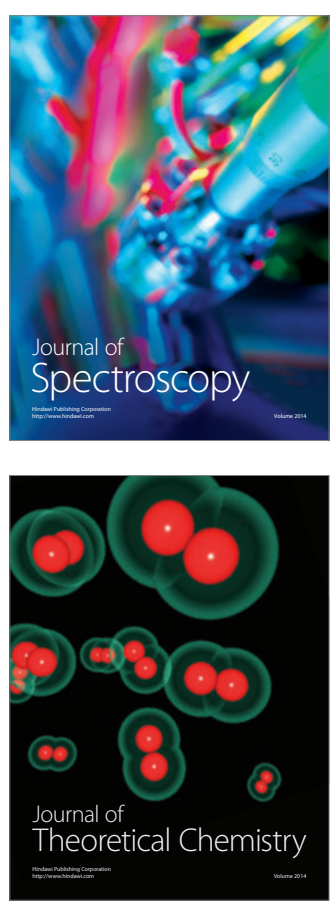
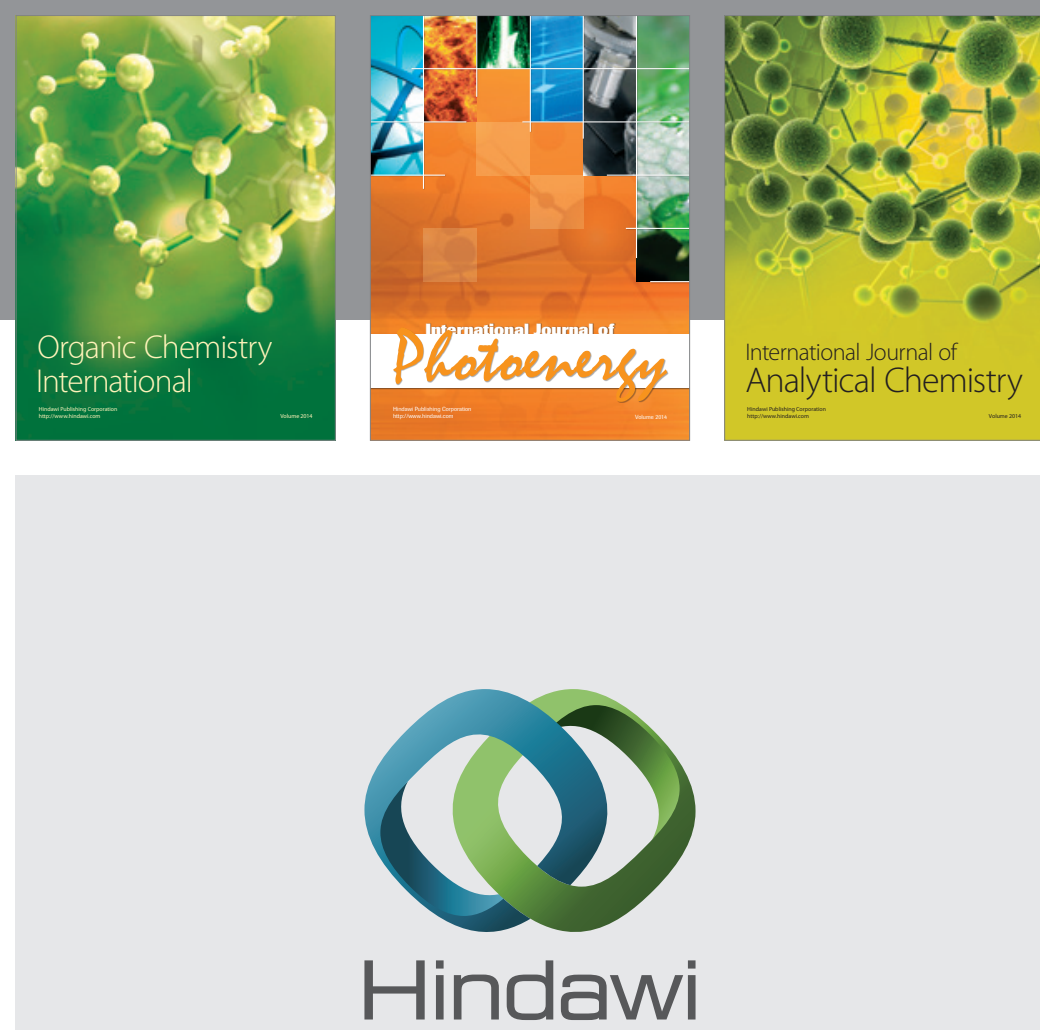

Submit your manuscripts at

http://www.hindawi.com
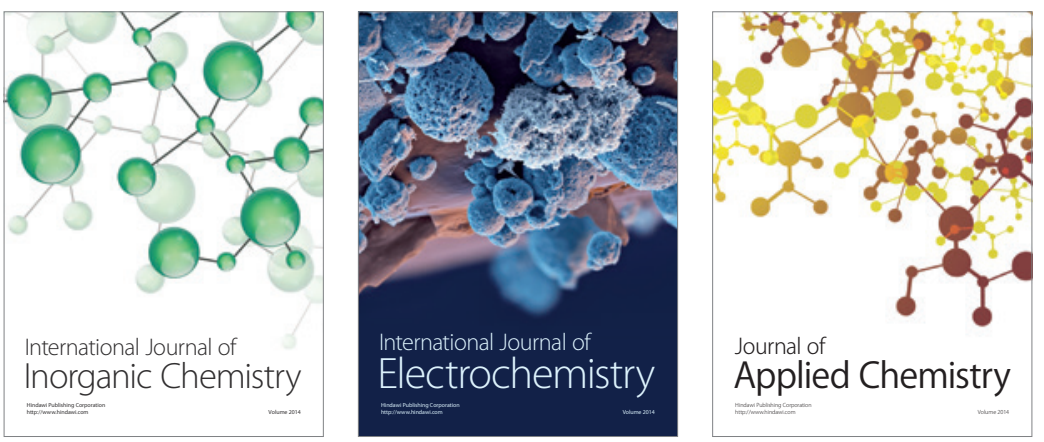

Journal of

Applied Chemistry
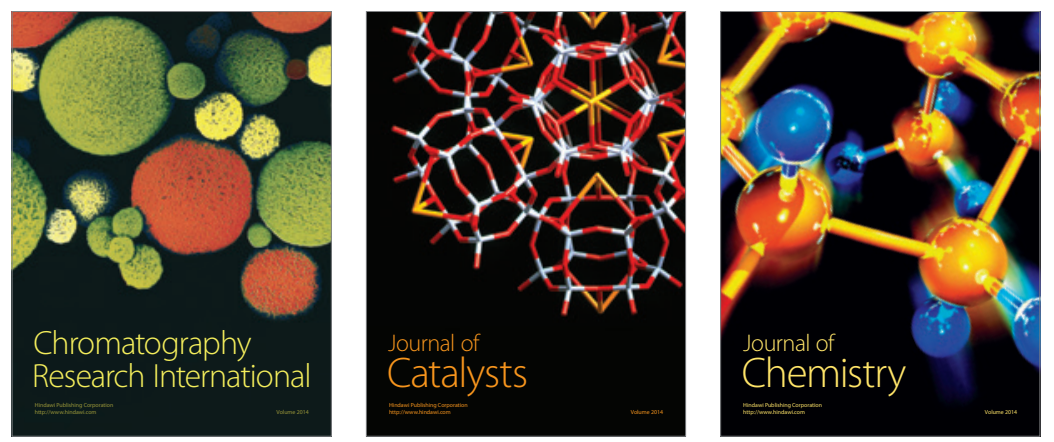
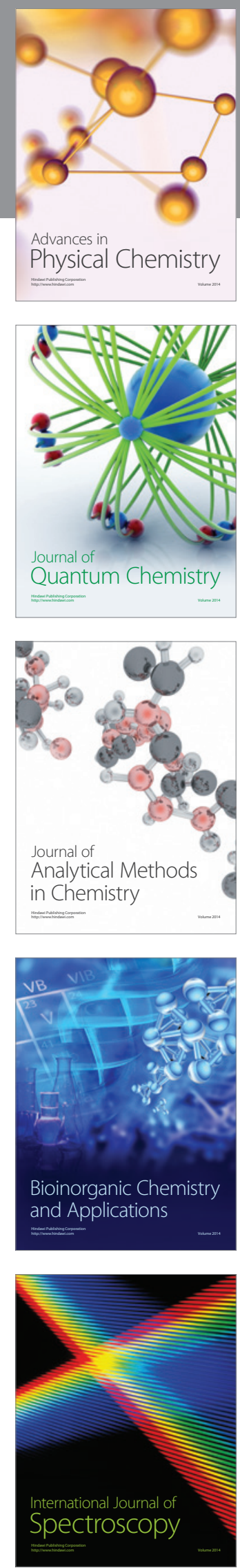